\title{
Experiences on Participation in Literary Activities: Intellectual Stimuli Empower People with Mental Health Problems
}

\author{
Lisbeth Kristiansen, Ulrika Lif, Helen Asklund \\ Mid Sweden University, Sundsvall, Sweden \\ Email: ulrika.lif@miun.se,helen.asklund@miun.se,lisbeth.kristiansen@miun.se
}

How to cite this paper: Kristiansen, L., Lif, U. and Asklund, H. (2017) Experiences on Participation in Literary Activities: Intellectual Stimuli Empower People with Mental Health Problems. Open Journal of Nursing, 7, 1307-1323.

https://doi.org/10.4236/ojn.2017.711094

Received: October 7, 2017

Accepted: November 20, 2017

Published: November 23, 2017

Copyright (c) 2017 by authors and Scientific Research Publishing Inc. This work is licensed under the Creative Commons Attribution International License (CC BY 4.0).

http://creativecommons.org/licenses/by/4.0/

\begin{abstract}
Some research acknowledges engagement in creative and literary activities as constructively impacting rehabilitation and recovery. Nevertheless, there is a deficit of literature describing experiences of participation in literary activities. This study examined how members of a non-profit association for mental health, with experiences of mental problems or illnesses, experienced group-based literary activities facilitated of a bi-disciplinary research team during one semester. This study held a constructive/naturalistic design and used a qualitative methodology with a latent analysis to describe how participants experienced literary activities (creative writing, reading and conversations about published and own written poetry and prose texts). Both individual and focus-group interviews were performed early 2014. Despite previous negative experiences, the findings showed that the participants perceived the literary activities empowering. Four categories were created: Presumptions of personal literacy, leadership role, participants' role, and literacy development. These were abstracted and interpreted into three themes: Identifying a reading and writing self-image, challenging and redefining one's reading and writing identity, and strengthening one's intellectual and humanistic capacity. Literary activities seemed to positively change the participants' attitudes towards writing and reading, and also enhanced their literacy skills. We argue that literacy skills are interconnected with health literacy. Involvement of literary activities into rehabilitation in mental health practice may be beneficial for some groups, and merits further studies.
\end{abstract}

\section{Keywords}

Alternative Interventions, Literary Activities, Mental Health Promotion, Multidisciplinary Care, Qualitative Methodology, User Involvement 


\section{Introduction}

Given the huge burden of mental health problems, there is a need to widen and re-think the concepts of treatment and recovery. Intellectual stimuli and challenge, here in the form of literary activities, may contribute. The focus of this paper is the bi-disciplinary area of nursing science in combination with the field of comparative literature. It pilots the content and form of a literary activity intervention targeting promotion of well-being among people with experiences of mental health problems.

\subsection{Background}

Mental illness constitutes $14 \%$ of the global burden of disease [1]. Mental disorders increase the risk of co-morbidities such as cardiovascular disease, diabetes, cancer and vice-versa [1] [2] [3], and because these conditions are often accompanied by stigmatization and poverty, it leads to human suffering and enormous challenges globally. These challenges should be addressed with a wide range of actions and interventions both in the societal/public/community and on the individual/family level. Psycho-educative and lifestyle interventions targeting the individual behavior aim to affect patients'clients' mental health and well-being [4] [5]. In its focus on peoples' well-being, narrative theory is seen as a useful explanatory model, because this theory emphasizes the importance of human storytelling in creation and recreation of self [6] [7].

\section{Possible Link between Cultural-Literary Activities, Health and Well-Being}

There is growing interest in that active involvement in creative activities provides benefits, such as the promotion of well-being, quality of life, health and social capital [8]. A population based study showed evidence of an existing arts engagement-mental health relationship, where those who engaged in arts activities 100 hours yearly or more reported significantly better mental well-being than others [9]. A number of British projects offered Arts on Prescription for people experiencing mental health problems and social isolation, and the results proved to help people recover [8]. Along similar lines, participants experienced an art project as improving self-worth, emancipating self from mental illness labels, also offering a sense of belonging, enabling acquisition of valued skills and offering meaningful occupation [10]. Furthermore, individuals affected by severe mental illness in mental health care settings experienced that creative writing constituted an important part of the recovery [7]. Nonetheless, due to the lack of consistency of a clear definition of health and well-being, it was difficult to establish the benefit of participating in creative arts [11]. This study also showed that creative arts might have potential as transformational tools, rather than an intervention for therapeutic diversion [11]. We strived to link a supposed positive change with a transformational tool-the intervention's literary activities-, where one outcome may be an enhanced participant health literacy. In this con- 
nection, health literacy comprises individual cognitive and social skills used to obtain, understand and act on information about health issues in ways that promote and maintain health [12].

\subsection{Theoretical Framework}

Jean Watson's transpersonal caritative philosophy/theory [13] served as one part of the theoretical framework behind this study. One central part of the theory emphasized the attended and focused listening, and conscious interpersonal presence. If human beings are provided a space and a good atmosphere where they are attended and listened to in a deep and confirming manner, verbalizing personal stories may actively enhance healing [13]. The other interconnected framework was the holistic theory that stated the mind's, the body's and the soul's inseparable unity [14]. This holistic view on humanity meant that one change, for instance in the form of intellectual/mind stimulus by taking part in guided creative writing and reading activities, may influence the person's other modalities. This might also enable a transitional process especially if it is done in a transpersonal caring manner. Still, there is a need to develop an evidence base and to investigate the value and effectiveness of the arts, including literary activities, in mental healthcare contexts [7] [15].

Aim

The study aimed to describe the participants' experiences of taking active part in group-based literary activities over one semester. The study participants were all members of a non-profit association.

\section{Method}

\subsection{Study Design}

The study held several assumptions in line with constructivist/naturalistic paradigm, for instance that multiple and subjective realities co-existed, that knowledge may be achieved by taking part in the informants' experiences and lifeworlds, and that knowledge could be co-created by informants and researcher/interviewers [16]. A qualitative design with an inductive approach was chosen in order to examine and understand variations in participants' experiences of the value of literary activities from their perspectives. Qualitative manifest and latent analysis inspired by Guba [17], Graneheim and Lundman [18] was, considering the aim, judged as the most appropriate to use.

\subsection{Settings and Participants}

All study participants had experienced or had mental health problems. They were also all members of a local section of the national association on mental health and social issues, an organization that regularly arranged different forms of activities for the members. The intervention participants were, therefore, all familiar with each other beforehand. Some of the demographical features of the 
participants were that the majority lived an independent life in their own apartments or houses. At the time of the study, most of them did not get support from mental health community services. There was a rich variety in terms of their daily occupations: some were employed at ordinary workplaces, while others were studying or receiving governmental retirement payments due to functional disability.

Out of approximately 50 individuals that were available, we asked who had interest in participating in the literary activities. This resulted in that we recruited thirteen participants who were invited to participate in the pilot. To be included in this qualitative interview study the participants should have attended at least $80 \%$ of the sessions. During the intervention phase, some merely attended a few intervention sessions, and they were therefore excluded from the interviews. In December 2013 we included five informants and they all agreed. The participants were aged between 25 and 65, and all had prior experiences of moderate to severe mental disabilities or mental illness.

\section{Intervention with Literary Activities}

Every second week during the autumn semester 2013, one session was held at the university campus. All together eight sessions took place. Each session lasted for two hours and was divided into two parts, please see Figure 1 below. They consisted of literary activities such as: 1) reading aloud and having booktalks, 2) working on creative writing exercises followed by discussions about texts written by the participants. In addition, the participants read prose texts at home, which were subsequently discussed in booktalks. The facilitators and the group members jointly decided the choice of literature for reading.

The pilot design of the literary activities methodology was, with inspiration from others, developed by the authors, and tested for participant feasibility. The book talks were inspired by Chambers' method ([19], pp. 100-107), where a "wondering" approach is established. Philips et al. [20] and Sampson [21]

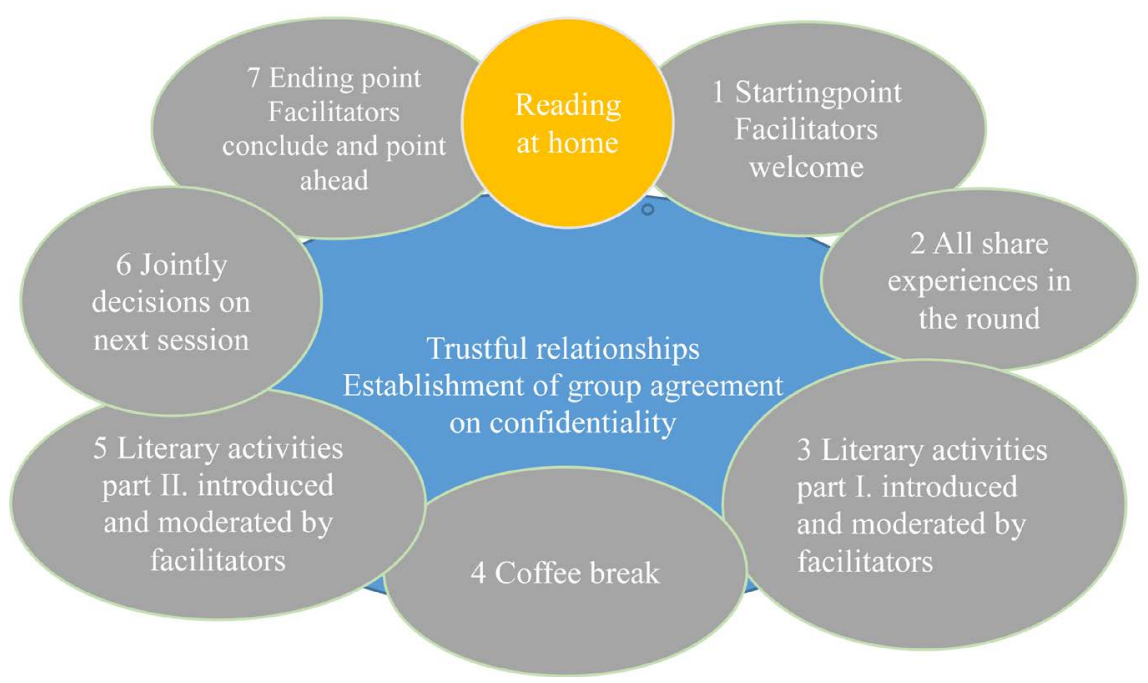

Figure 1. An overview of the intervention structure. 
inspired the creative writing component of the intervention. In general, the writing exercises lasted no more than ten minutes and were performed both individually and in small sub-groups.

\subsection{Data Collection}

Due to practical circumstances, three individual semi-structured interviews were conducted [22] referred to as interview I, II, and III, and further three informants took part in one focus group interview [23] referred to as interview IV in the finding section. One of the participants were interviewed both individually and in the focus group. All face-to-face interviews lasted approximately one hour. Prior to the start of the interview the aim of the study was repeated to ensure that the informant had understood its objective. The participants reflected upon the following over-reaching question: How did you experience taking part in the literary activities intervention? Clarifying questions were posed in order to make the informants elaborate their questions. The informants and the interviewers (three female researchers/authors/facilitators) were well acquainted with each other by the time of the data collection that took place at the university.

\subsection{Data Analysis}

The audiotaped interviews were transcribed verbatim (producing 42 double-spaced pages). The qualitative data were subsequently analysed by qualitative content analysis [17] [18]. The analysis was first performed on a manifest level, focusing on what participants actually expressed during the interviews. Meaning units were identified based on text that dealt with the same content. These meaning units were condensed while retaining their essential meaning. The next step was coding. Here the condensed units were coded, abstracted, labelled and sorted into sub-categories and categories. Each category consisted of data that had something in common and were considered mutually exclusive. Finally, based on interpretation and abstraction of how the experiences appeared, themes were created, while keeping the study as a whole in mind. This corresponded to a latent analysis (Table 1).

\subsection{Ethical Considerations}

Each participant provided informed and written consent to participate in the

Table 1. Examples of the analysis.

\begin{tabular}{cccccc}
\hline $\begin{array}{c}\text { Meaning } \\
\text { units }\end{array}$ & $\begin{array}{c}\text { Condensed } \\
\text { meaning units }\end{array}$ & Codes & Sub-categories & Categories & Themes \\
\hline $\begin{array}{c}\text { I. but this... } \\
\text { I grew up } \\
\text { with }\end{array}$ & $\begin{array}{c}\text { The } \\
\text { interviewee } \\
\text { reading... to } \\
\text { read at home } \\
\text { is something } \\
\text { I grew up } \\
\text { with reading } \\
\text { at home }\end{array}$ & $\begin{array}{c}\text { Statement } \\
\text { on reading }\end{array}$ & $\begin{array}{c}\text { Promoters of } \\
\text { reading and } \\
\text { writing }\end{array}$ & $\begin{array}{c}\text { Presumptions of } \\
\text { the personal } \\
\text { literacy }\end{array}$ & $\begin{array}{c}\text { Identifying } \\
\text { one's reading } \\
\text { and writing } \\
\text { self-image }\end{array}$ \\
\hline
\end{tabular}


study, and were thoroughly briefed beforehand and guaranteed confidentiality. Their diagnosis were not judged relevant to our study, therefore, we consciously avoided asking. The procedures accorded with the Declaration of Helsinki [24], and the study is part of a larger study that gained permission from the regional ethical committee (Dnr 2012-363-32M).

\section{Findings}

As seen in the finding section below, three separate themes were formulated capturing the participants' experiences. These were: "Identifying a reading and writing self-image", "Challenging and redefining one's reading and writing identity" and "Strengthening one's intellectual and humanistic capacity". The findings were divided into two domains that reflected the situation before the intervention as well as its outcomes (Table 2). In the informants' citations the signs meant: (authors comments) and [that text has been left out] and (X, Y, Z different persons in the FG).

\subsection{Identifying a Reading and Writing Self-Image}

Generally, the participants had not previously reflected on their relationship to reading and writing. Nonetheless, they held strong opinions and clear pictures

Table 2. Provides an overview of the domains, sub-categories, categories, and themes.

\begin{tabular}{|c|c|c|c|}
\hline Domains & Sub-categories & Categories & Themes \\
\hline \multirow{5}{*}{$\begin{array}{l}\text { Reflections on } \\
\text { pre-intervention } \\
\text { period }\end{array}$} & $\begin{array}{l}\text { Promoters of reading } \\
\text { and writing }\end{array}$ & $\begin{array}{l}\text { Presumptions of } \\
\text { personal literacy }\end{array}$ & $\begin{array}{l}\text { Identifying a reading and } \\
\text { writing self-image }\end{array}$ \\
\hline & $\begin{array}{l}\text { Obstacles for reading } \\
\text { and writing }\end{array}$ & & \\
\hline & $\begin{array}{l}\text { Structured literary } \\
\text { group activities }\end{array}$ & Leadership role & $\begin{array}{l}\text { Challenging and } \\
\text { redefining one's reading } \\
\text { and writing identity }\end{array}$ \\
\hline & $\begin{array}{l}\text { Inclusion and } \\
\text { empowerment }\end{array}$ & & \\
\hline & $\begin{array}{l}\text { Non-competing and } \\
\text { non-judgmental } \\
\text { atmosphere }\end{array}$ & & \\
\hline \multirow[t]{4}{*}{$\begin{array}{l}\text { Reflections on } \\
\text { participation }\end{array}$} & $\begin{array}{l}\text { Awareness of and } \\
\text { exposure to other's } \\
\text { perspective }\end{array}$ & Participants role & \\
\hline & Trust and courage & & \\
\hline & Intellectual stimuli & $\begin{array}{c}\text { Literacy } \\
\text { development }\end{array}$ & $\begin{array}{l}\text { Strengthening one's } \\
\text { intellectual and } \\
\text { humanistic capacity }\end{array}$ \\
\hline & $\begin{array}{l}\text { Ability to understand, } \\
\text { interpret and write } \\
\text { fiction texts }\end{array}$ & & \\
\hline
\end{tabular}


on this matter. During the intervention they began to think about their self-images in terms of what and how they used to read and write. The participants' reading and writing self-images were mirrored in the theme "Identifying a reading and writing self-image", which was created based on the category "Presumptions of personal literacy".

\section{Presumptions of Personal Literacy}

This category described what the interviewees carried with them prior to the literary activities intervention. It dealt with prerequisites for joining the intervention as well as the participants' assumptions about their own reading and writing capacities. This category was based on the following sub-categories: "Promoters of reading and writing" and "Obstacles to reading and writing".

\section{1) Promoters of reading and writing}

The participants' previous positive experiences of reading and writing that had affected their personal history were taken into account. Above all, thissub-category was influenced by the participants' social and cultural heritage, including their earlier school experiences. One participant stated that her/his whole family used to go the library and have a fun time together. Some had been introduced to reading in their home environment and were since an early age accustomed to, and felt comfortable having, books, around them. One of the participants, for whom reading and writing filled a vital role, expressed that for him/her, writing was a way of processing experiences, whereas reading:

"... is one of the most important sources of who I am today." (Interview I)

Some participants were early readers and developed strong reading habits. One participant expressed an explicit appreciation for the ability to maintain concentration:

"I learned how to read when I was quite young-I was maybe five years old or so. I read a lot even then, so maybe I m used to reading a lot... Yes, it's so good that $\mathrm{Pm}$ able to concentrate on this (reading) too. Actually, it surprises me. There is so much else that I have difficulty getting done, like with concentration." (Interview III)

Simultaneously, some participants considered reading a relaxing pastime, but also a way of escaping from their problems and the difficulties of life:

"Yes, to get away from what $1 \mathrm{~m}$ brooding over in my everyday life... I get away from my thoughts, and that is very comforting." (Interview III)

Our findings revealed that in order to want to read and write, however, motivation and curiosity are needed. If the text did not seem interesting, the reading became tiresome.

\section{2) Obstacles to reading and writing}

Whereas the findings revealed several examples of factors that promoted the participants' reading and writing, many obstacles also emerged. In the interviews, it became obvious that some participants had been raised in social contexts that did not naturally involve a reading and writing tradition. Furthermore, some participants had had bad experiences in their school years, which they ex- 
perienced as negatively occupied with a one-dimensional focus on performance and results. Some felt uncomfortable with the way they had been taught. As described below, the retold memories were frequently related to reading and writing self-images:

"When I went to school I couldn't write freely, so I had to go to a special needs educator and was placed in a small group. It was very problematic. This continued almost til the end of upper secondary school, when I got a teacher who was very encouraging... So then, in the last one and a half years, I wrote in school, and after that I have written at times... But it was very problematic when I was a child, since writing was such a big part of school..." (Interview III)

Others disclosed reading and writing disabilities or other issues that had made their reading and writing experiences negative throughout their lives:

“... I never got the intellectual foundation... [...] Nobody ever read fairy tales to me or helped me with my homework... that probably explains why I am a little 'disordered now... Or disordered, something is lacking within me..." (Interview IV)

In addition, some participants described an obstacle stemming from the fact that they were often simply too tired to read or write. One pointed to a lack of energy to get started with these kinds of assignments:

"... but then I postponed it to the very last evening. And then maybe I got started, but I was so tired that I didn't have the strength to end it properly...” (Interview I).

\subsection{Challenging and Redefining One's Reading and Writing Identity}

The participants referred to the intervention period as a time when they reflected on how they faced reading, writing and booktalks, and where they challenged themselves to deal with these situations in new ways. The findings revealed the ways in which the sessions enabled participants to redefine their earlier self-images in terms of literary activities. This theme also dealt with the actual organization and structure of the literary activities and the spirit in which they were performed. The theme was based on two categories: "Leadership role" and "Participants' role".

\subsubsection{Leadership Role}

The findings revealed the significance of the structure and the leaders' approach to the participants' involvement. This category was based on an abstraction of the following three sub-categories: "Structured literary group activities", "Inclusion and empowerment" and "Non-competing and non-judgmental atmosphere".

\section{1) Structured literary group activities}

It seemed that the different forms of literary activity made the participants rethink their presumptions about their reading and writing identities. The most widely appreciated aspects of the intervention involved the working elements of 
listening and discussion:

"It leads to a completely different level when discussing literature and writing. [...] ...that we' re gathered around a topic, and we are of course as well led, so to speak." (Interview IV)

The writing component was widely regarded as challenging:

“...to write has been a challenge for me, and to read together and talk about the texts... I think it has been very rewarding to be a part of (the intervention)..." (Interview IV)

This also meant that the participants' pre-fixed picture of themselves as "poor" writers could be challenged by the intervention's structure, with its short and distinctly defined exercises. One participant, who used to feel forced into and limited by traditional school's normative writing rules, expressed that the intervention's structure allowed him/her to take another approach:

“... when it comes to writing, it has always been like this... as soon as you have a goal, this is the way you are supposed to perform... this is the correct writing style. Then writing becomes very frustrating for me. It becomes very difficult, because then I start to think of all the different sections and parts that I must divide the text into... instead of just starting to write and then doing the division later. While if you are given only a framework, it might be easier just to keep going. [...] writing has never been my cup of tea, because school made it so very negative. [...] this (intervention) was completely different from school. [...] It has been a challenge for me, but I have been prepared to take it on, and I also wanted to try and see what the others had written and listen to them... and think about it. Well, there are a lot of styles and a lot of variation, and if you write that only depends on you. But if you listen to all of the others, you see there's so much more to it, which is something I have appreciated here. [---] Not that I strive... for it, but I just understood, wow, I can deal with writing, even though I have some boundaries (set by the facilitators). I can still perform" (Interview II)

\section{2) Inclusion and empowerment}

In addition to describing the importance of the structure of the literary group activities, the participants pointed out the importance of the leaders' including and reinforcing approach and responses during the sessions. This led to the participants feeling encouraged and acknowledged, as three different participants expressed in the following:

“... for me, it meant a lot to get encouragement. It was positive in that regard, because I am very sensitive to negative critique, and here it has been positive. This means a lot to me". (Interview II)... "It is an art form to be able to listen, confirm and show that you have listened and to ask questions. That plays an enormous role. $(X)$..." "Yes, that you are guided, you are triggered... you are challenged. That wouldn't happen if nobody leads or if the people are not engaged in and like what they are doing. Otherwise, it just gets superficial, and then it becomes meaningless ( $Y$ )..." (Interview IV)

3) Non-competitive and non-judgmental atmosphere 
All interviewees stated that the group's atmosphere was crucial to making them feel safe in contrast to experiences that most of them had previously had. It was important to them that they were not negatively judged and that they did not "compete". An important factor held responsible for this was that the leadership reminded about and encouraged a non-competitive and non-judgmental way. The phenomenon of the participants easily putting inherent demands on themselves was touched upon in the focus group discussion:

"There's the challenge for me, to find the right mood and the joy that makes me feel alive and motivated, despite the fact that these activities can pretty easily be connected to performance. $(\mathrm{Z})$ “... you have this feeling, even thoughts, that it is not real... that is why... I have been very surprised by the fact that I have been able to manage in a calm and relaxed way... Earlier I would probably have been frustrated and mad at myself. But this time I managed. ( $Y$ )" (Interview IV)

However, one interviewee expressed the fact that she/he was unable to remain unaffected by the others:

"When there is time pressure, my mind can go blank. This happens nowadays. Maybe it was different when I was younger. Then I notice: He's writing, he's writing, and I don't know what to write. I might have written four lines, and he has written 54 lines." (Interview I)

\subsubsection{Participant Role}

The whole idea of conducting an intervention based on literary activities is premised on the concept of active participants in a safe environment where new experiences had the possibility to emerge. This category was created and built on the following two sub-categories: "Awareness of and exposure to others' perspectives" and "Trust and courage".

\section{1) Awareness of, and exposure to, others' perspectives}

During the sessions the participants had frequent discussions, and in the findings it became obvious that they observed their genuine differences in opinions and thoughts and appreciated being exposed to others' reflections and opinions. This was reflected in the focus group interview in the following way:

“... just to be a part of a group and being able to discuss... when other people have ideas/thoughts that go against your own... that you might be able to accept what other people say." and by another group member: ".... I think the fact that you gather around something mutually and meet other people can be fruitful, and I think this goes also for people who have been suffering from (mental) illness for a long period of time..." (Interview IV)

\section{2) Trust and courage}

The participants described how they felt reinforced in an environment where they could dare to work from the unknown and challenge themselves. They viewed themselves as more courageous and built up a feeling of trust. One of them put these feelings into these words:

"To practice social skills a bit... that you can dare say something about what you think. Maybe read aloud-there are many who have a lot of problems with 
that, too. Write, and then dare to share that, too. Because I believe that everything we do here is still a personal ability, a personal interpretation of something. Many times people have had tremors in their hands over even small things we have shared, and so it's a good exercise to get around that. But it is important that you dare to believe in the group, and believe also in the concept, because very much is, after all, about daring to trust a little bit'. (Interview II)

The courage and capability of letting go of fears that the participants gained was connected to performance and inherent demands. Their ability to rejoice in others' points of view is also clear in the following quotation:

"I feel the same: for once I haven't been so focused on results or performance. On my own performance, but yes, exactly as you say yes, let's do this, [the exercises] become a challenge, and then IIl see what comes out of them. This is what's exciting, to see what will come out, and this depends on my daily health status and how I feel and everything around me, so it has been interesting. In addition to this, P $m$ curious too, so it has been enjoyable to listen to what the others have written and said and so on". (Interview IV)

\subsection{Strengthening One's Intellectual and Humanistic Capacity}

The participants felt strengthened, as they experienced how they deepened their understanding, broadened their perspectives by including others and literally accomplished more. This theme was also accompanied by emotions of relief, joy and renewal, and it was based on the category "Literacy development".

\section{Literacy Development}

The findings revealed that the intervention environment provided intellectual stimulation that also touched upon human existential matters and offered a challenging space with respect to participants' earlier experiences as "academic" performers. This category was abstracted from two sub-categories:"Intellectual stimuli" and "Ability to understand, interpret and write fiction texts".

\section{1) Intellectual stimuli}

This sub-category dealt with how the participants were intellectually stimulated by multiple dialogues with the texts, the writing exercises, their peers and their own beliefs and thoughts:

"Yes, I immediately think of intellectual stimuli, and that means a tremendous amount to me. I haven't understood this until now, rather late in life, the importance of taking care of this need as well. And yes, for me culture is fantastic, yes... for me it's very attached to the emotional life... And this, during this course, just getting the chance to take part of other people's different thoughts, points of view and reflections, that's fantastic, yes, I feel. I experienced personal growth, and not only that, but I also had a good time. It was very fruitful. Even though sometimes we discussed difficult topics and so on, these subjects made me feel alive, because, for my part, they kind of touch the right area..." (Interview IV)

Further, the participants more easily shifted their perspectives and understood their co-participants' and facilitators' points of view, and at times they also ques- 
tioned the arguments and perceptions expressed. They stated a satisfaction with the possibility of expanding their own horizons related to their intellectual ability:

"... and have to learn new stuff, and so it is important that we are being challenged, that, yes, now we'll write here. Now we do it here. And it's not common. As well, it's been great fun [...] ... to see how other people reflect completely different from me... it has been enriching." (Interview IV)

Participants saw others' reflections on the discussed poetry and prose texts as significant:

"For me... it has been life-enhancing to anticipate other people's thoughts. Not necessarily about their whole lives and what they want from life. But mostly their thoughts... It as a bonus for me to escape the straitjacket that school was for me". (Interview II)

\section{2) Ability to understand, interpret and write fiction texts}

The participants expressed that they were able to understand and interpret fiction in ways that they had not experienced before. They emphasized a new depth and widened perspectives while reading, for example in the following:

"I reflect more now when I read. [...] I (usually) read a lot at home, so therefore this has benefitted my reading at home as well." (Interview IV)

Another interviewee described a strengthened ability to understand and interpret fiction:

“...I think that when we read a piece and then discussed the characters... I've always been interested in understanding (human issues), to identify different characters in different patterns, [...] and this is what we have done... but, funny enough I haven't thought about this with regard to literature. Or maybe I have done so unconsciously, and I have never discussed as deep as we have done here, that's something completely new to me. Very interesting?' (Interview IV)

With regard to writing ability, one of the participants expressed a sense of discovery:

"And when you say 'write something', I got to hold the pen and then... one paper filled at once. You know, this is something inside me that I didn't believe existed'. (Interview III).

Participants also expressed a sense of relief linked to the creative writing exercises:

"I remember the last session... there were absolutely more different kinds of writing than there were people at the session. [...] I think that is very interesting. I have gained most from the writing part, because it feels like I was finally able to let go of the heavy burden from my school years, and in some respect I have been released and feel, okay I can do this" (Interview II).

\section{Discussion}

\subsection{Literary Group Activities Add Value and Meaning to Human Experiences}

The qualitative designed study strived to capture the feasibility of the intervention on literary activities for people with ongoing or previous experiences of 
mental ill health. The specific aim was to describe the participants' experiences of taking active part in regular, group-based literary activities over one semester. The study participants were all members of a non-profit association for mental health. It should be noted that the findings were based on participants that were positive to the taking part in the pilot, and not on a sample reflecting the general population. In summary, the main findings showed that participation in literary group activities prompted the interviewees' identification of their reading and writing self-image, that they redefined their reading and writing identity, and furthermore that their intellectual and humanistic capacities were strengthened. However, social circumstances and childhood experiences formed the participants' presumptions of personal literacy and played an important role, as did whether they found it relaxing or difficult to read and write. The literary activities intervention provided the participants an opportunity to give voice to their literacy history. Most importantly, the participants transformed their previous, generally negative literary self-image into a more dialogue oriented, skilled and competent one.

In the study findings, we learned that the participants gained and experienced more empowerment through the intervention, and they appreciated the actual reading, writing and booktalks involved. This might be similar to the transformative potential of arts [11]. Furthermore, they emphasized that these experiences were due to the intervention's structured content as well as its leadership and their own active participation, which was seen as the opposite to the socialization in connection with "coffee party", as one of the participants expressed. The literary activities per se and the intervention's intellectual stimuli generated qualitative differences. Lawson et al. [11] observed that participation in arts activities enabled acquisition of valued skills and offering meaningful occupation and routines.

\subsection{The Concept of Literacy and Its Possible Link to Health Literacy}

It should be mentioned that Sweden has a 150 years old tradition that mandates school attendance for all children. This tradition could be seen as interconnected to the concept of literacy, which has its roots in linguistic science and means the general ability to read, write and understand written texts as well as to interpret them. The findings suggest that the participants strengthened their general literacy skills, and that combined with their experience of an elevated sense of self-efficacy and enhanced empowerment [25], this could be transformed into a higher level of working health literacy. Requirements for good health literacy also include access to relevant and trustworthy information, which helps make an individual and active partaker engaged in choosing personal treatments and health decisions.

\subsection{Consequences of Lacking Literacy and Health Literacy}

In contrast, limited health literacy may be an underestimated cause of difficulties 
in treatment and rehabilitation [26]. Some sub-groups are identified as possessing fewer health literacy skills and resources than others possess, which underlines the potentially important role of health literacy in the development of equitable interventions to improve health outcomes [27]. For instance, a review demonstrated that low health literacy was consistently associated with more hospitalizations, poorer ability to demonstrate taking medications appropriately, poorer ability to interpret health messages, poorer overall health status and higher mortality rates [28]. Furthermore, depression and literacy status are seen as the most important factors associated with missed health care appointments, although regular screening for depression and literacy status as well as interventions can be utilized to help decrease the rate of missed appointments [29].

\subsection{Telling One's Story and Being Listened to Heals}

In addition, we understand the present findings as when people are engaged in reading, writing and reflecting on the lives of fictional characters, it encourages them to narrate their own personal stories ( $c f .[6]$ ). According to Watson and Foster [13], when nurses provide patients space and time with authentic listening, the verbalizing of the patients' personal stories actively enhances healing. This might counteract institutionalized care that often resemble human warehouses rather than places of healing [1]. The extended ability to understand other's perspectives might indicate an enhanced empathic ability, which is in line with the findings of Bertman [30], who showed that fictional texts have capacity to engage readers to expand their depth of emotional understanding and insight, essential for growing empathic responses. Taken together these components correspond to the core of humanistic skills and values. Besides, participation in literary activities might lead to a better understanding of health information, which in turn leads to more qualified health service users. This again would provide greater equality, democracy and societal influence for what is generally regarded as an under-privileged group (cf. [31]).

\subsection{Conclusion and Clinical Implications}

It seemed as if the intervention in form and content felt feasible because the participant throughout the pilot period as well as in the qualitative interviews expressed their experiences of meaningfulness and joy when engaged in the literary activities intervention. Based on the findings it seems reasonable to conclude that this literary activities pilot challenged the participants' previous self-image, and that it contributed to a transitional process towards greater literacy-related self-image. Besides, the participants and the intervention leaders should jointly be able to create and reinforce a listening, positive and caring environment. In order to be able to implement the intervention by health care organizations or in the primary health care context as a complement to target mental health issues, further research is required.

Given the findings, it seems worthwhile to make further investigations by us- 
ing another design to enable drawing conclusions on another level. In future testing the hypothesis that literary activities generates enhanced health literacy is also of value.

\section{Methodological Considerations}

Besides the very small amount of pilot participants, one weakness indeed is that the authors both had the role as intervention designer/developer/facilitators and data collector. In addition, we did not scientifically investigate the reasons why the majority of the 13 originally recruited members did not fulfill the participation. However, we learned that it was hard for them to prioritize the sessions as it sometimes collided with other activities or because, they simply did not have enough energy. This may have implications for the findings relevance and acceptability as the form and content to not "fit all". The fact that one of the participants was interviewed both individually and in the focus group, did not affect the findings. Regarding aspects of the study's trustworthiness, we believe that its credibility was enhanced by the fact that we focused on and approached an appropriate sample of the research question [17], and chose relevant units of analysis. The authors have elaborated all parts of the analysis jointly and discussed until we reached consensus, which indicate good dependability. We believe that the readers are provided with sufficiently detailed information on the study's context and tight descriptions to make an independent judgment of the research's transferability into other, similar contexts [18].

\section{Acknowledgements}

We would like to thank the participants for their engagement in the study. Further, we thank the department of humanities and the department of nursing sciences at Mid Sweden University for financial support.

\section{Conflicts of Interest}

The authors declared no conflicts of interest.

\section{References}

[1] WHO. WHO Mental Health Gap Action Programme (mhGAP). http://www.who.int/mental_health/mhgap/en/

[2] Carta, M.G., Conti, A., Lecca, F., et al. (2015) The Burden of Depressive and Bipolar Disorders in Celiac Disease. Clinical Practice \& Epidemiology in Mental Health, 11, 180-185. https://doi.org/10.2174/1745017901511010180

[3] Millman J., Galway K., Santin O., et al. (2015) Cancer and Serious Mental Illness-Patient, Caregiver and Professional Perspectives: Study Protocol. Journal of Advanced Nursing, 72, 217-226.

[4] Baruah, A., Bhaduri A. and Deuri SK. (2012) Effect of Psycho-Educative Intervention on Knowledge about Illness and Self-Care in Patients with Schizophrenia. Nursing Journal of India, 103, 188-190.

[5] Rönngren, Y., Björk, A., Haage, D., et al. (2014) LIFEHOPE.EU-Lifestyle \& Healthy Outcome in Physical Education: Development of a Lifestyle Intervention 
Program for People with Severe Mental Illness: Physical Activity, Dietary Changes, and Cognitive Adaptation Training. Journal of Psychiatric and Mental Health Nursing, 21, 924-930. https://doi.org/10.1111/jpm.12175

[6] Bruner, J. (2004) The Narrative Creation of Self. In: Angus, L.E. and McLeod, J., Eds., The Handbook of Narrative and Psychotherapy. Practice, Theory and Research, Sage Publications, London, 3-14. https://doi.org/10.4135/9781412973496.d3

[7] King, R., Neilsen, P. and White, E. (2013) Creative Writing in Recovery from Severe mental Illness. International Journal of Mental Health Nursing, 22, 444-452. https://doi.org/10.1111/j.1447-0349.2012.00891.x

[8] Bungay, H. and Clift, S. (2010) Arts on Prescription: A Review of Practice in the UK. Perspectives in Public Health, 130, 277-281.

https://doi.org/10.1177/1757913910384050

[9] Davies, C., Knuiman, M. and Rosenberg, M. (2016) The Art of Being Mentally Healthy: A Study to Quantify the Relationship between Recreational Arts Engagement and Mental Well-Being in the General Population. BMC Public Health BMC series-Open, Inclusive and Trusted, 16, 15.

[10] Lawson, J., Reynolds, F., Bryant, W., et al. (2014) 'It's Like Having a Day of Freedom, a Day Off from Being Ill': Exploring the Experiences of People Living with Mental Health Problems Who Attend a Community-Based Arts Project, Using Interpretative Phenomenological Analysis. Journal of Health Psychology, 19, 765-777. https://doi.org/10.1177/1359105313479627

[11] Leckey, J. (2011) The Therapeutic Effectiveness of Creative Activities on Mental Well-Being: A Systematic Review of the Literature, Journal of Psychiatric and Mental Health Nursing, 18, 501-509. https://doi.org/10.1111/j.1365-2850.2011.01693.x

[12] Berkman, N.D., Davis, T.C. and McCormack, L. (2010) Health Literacy: What Is It? Journal of Health Communication, 15, 9-19. https://doi.org/10.1080/10810730.2010.499985

[13] Watson, J. and Foster, R. (2003) The Attending Nurse Caring Model: Integrating Theory, Evidence and Advanced Caring-Healing Therapeutics for Transforming Professional Practice. Journal of Clinical Nursing, 12, 360-365. https://doi.org/10.1046/j.1365-2702.2003.00774.x

[14] Cole, S.W. (2013) Social Regulation of Human Gene Expression: Mechanisms and Implications for Public Health. American Journal of Public Health, 103, 84-92. https://doi.org/10.2105/AJPH.2012.301183

[15] McArdle, S. and Byrt, R. (2001) Fiction, Poetry and Mental Health: Expressive and Therapeutic Uses of Literature. Journal of Psychiatric and Mental Health Nursing, 8, 517-524. https://doi.org/10.1046/j.1351-0126.2001.00428.x

[16] Creswell, J.W. and Poth, C.N. (2018) Qualitative Inquiry and Research Design Choosing among Five Approaches. 4th Edition, SAGE Publications, Inc., Thousand Oaks.

[17] Guba, E. (1981) Criteria for Assessing the Trustworthiness of Naturalistic Inquiries. Educational Technology Research and Development, 29, 75-91.

[18] Graneheim, U.H. and Lundman, B. (2004) Qualitative Content Analysis in Nursing Research: Concepts, Procedures and Measures to Achieve Trustworthiness. Nurse Education Today, 24, 105-112. https://doi.org/10.1016/j.nedt.2003.10.001

[19] Chambers, A. (2011) Tell Me: Children, Reading and Talk: with the Reading Environment. Thimble Press, Woodchester.

[20] Philips, D., Linington, L. and Penman, D. (1999) Writing Well. Creative Writing 
and Mental Health. Jessica Kingsley Publishers, London.

[21] Sampson, F. (2004) Creative Writing in Health and Social Care. Jessica Kingsley Publishers, London.

[22] Patton, M. (2015) Qualitative Research and Evaluation Methods: Integrating Theory and Practice. 4th Edition, SAGE, London.

[23] Kitzinger, J. (1996) Introducing Focus Groups. In: Mays, N. and Pope, C., Eds., Qualitative Research in Health Care, BMJ Publishing Group, London.

[24] WMA Declaration of Helsinki-Ethical Principles for Medical Research Involving Human Subjects. http://www.wma.net/en/30publications/10policies/b3/

[25] Nutbeam, D. (2000) Health Literacy as a Public Health Goal: A Challenge for Contemporary Health Education and Communication Strategies into the 21th Century. Health Promotion International, 15, 259-267.

https://doi.org/10.1093/heapro/15.3.259

[26] Wangdahl, J.M. and Mårtensson, L.I. (2015) Measuring Health Literacy-The Swedish Functional Health Literacy Scale. Scandinavian Journal of Caring Sciences, 29, 165-172. https://doi.org/10.1111/scs.12125

[27] Beauchamp, A., Buchbinder, R., Dodson, S., et al. (2015) Distribution of Health Literacy Strengths and Weaknesses across Socio-Demographic Groups: A Cross-Sectional Survey Using the Health Literacy Questionnaire (HLQ). Biomedical Central of Public Health, 15, 678. https://doi.org/10.1186/s12889-015-2056-z

[28] Berkman, N.D., Sheridan, S.L., Donahue, K.E., et al. (2011) Low Health Literacy and Health Outcomes: An Updated Systematic Review. Annals of Internal Medicine, 155, 97-107. https://doi.org/10.7326/0003-4819-155-2-201107190-00005

[29] Miller-Matero, L.R., Clark, K.B., Brescacin, C., et al. (2015) Depression and Literacy Are Important Factors for Missed Appointments. Psychology, Health and Medicine, 23, 1-10.

[30] Bertman, S.L. (1980) Lingering Terminal Illness and the Family: Insights from Literature. Family Process, 19, 341-348.

https://doi.org/10.1111/j.1545-5300.1980.00341.x

[31] Kristiansen, L., Hellzén, O., and Asplund, K. (2010) Left Alone-Swedish Nurses' and Mental Health Workers' Experiences of Being Care Providers in a Social Psychiatric Dwelling Context in the Post-Health-Care-Restructuring Era. A Focus-Group Interview Study. Scandinavian Journal of Caring Sciences, 24, 427-435.

https://doi.org/10.1111/j.1471-6712.2009.00732.x 